Editorial

\title{
The Politics of Inequalities in Education: Exploring Epistemic Orders and Educational Arrangements of Durable Disadvantaging
}

\author{
Kenneth Horvath ${ }^{1, *}$ and Regula Julia Leemann ${ }^{2,3}$ \\ ${ }^{1}$ Department of Sociology, University of Lucerne, Switzerland; E-Mail: kenneth.horvath@unilu.ch \\ 2 Department of Educational Sociology, University of Teacher Education FHNW, Switzerland; \\ E-Mail: regula.leemann@fhnw.ch \\ ${ }^{3}$ Department of Educational Sciences, University of Basel, Switzerland \\ * Corresponding author
}

Submitted: 4 August 2021 | Published: 16 September 2021

\begin{abstract}
The durability of educational inequalities marks a key problem for research and politics alike. Why do unwanted patterns of social sorting and disadvantaging in education prove so persistent, despite decades of research, debates, and reforms? This thematic issue of Social Inclusion aims to further our understanding of the factors and mechanisms underlying this persistence by putting the manifold entanglements of politics, inequalities, and social research centre stage. The collected articles inquire into various facets of this interplay, from the history and politics of the statistical quantification of educational inequalities to the political embedding of everyday pedagogical practices. The contributions cover a wide range of fields and topics, from non-formal education to school and higher education, from social selectivity in gifted education to subject formation in vocational education. Two strategic anchor points emerge from the collected articles for exploring and analyzing current arrangements of educational inequalities: (1) political and pedagogical epistemic orders and (2) educational arrangements that structure educational processes and situations. Ongoing social and political transformationsincluding the digitization and datafication of education and changing forms of governance-underline the pressing need for further research along these lines.
\end{abstract}

\section{Keywords}

education; social inequalities; politics of education

Issue

This editorial is part of the issue "Education, Politics, Inequalities: Current Dynamics and Perspectives" edited by Kenneth Horvath (University of Lucerne, Switzerland) and Regula Julia Leemann (University of Teacher Education FHNW, Switzerland / University of Basel, Switzerland).

(C) 2021 by the authors; licensee Cogitatio (Lisbon, Portugal). This editorial is licensed under a Creative Commons Attribution 4.0 International License (CC BY).

\section{Exploring the Politics of Persistent Inequalities in Education}

The Covid-19 crisis has, once again, highlighted the massive social disparities that mark current education systems across the globe. The pandemic seems to have exacerbated these already existing patterns that persist in spite of decades of problematization and debate in educational politics and research, and notwithstanding countless reforms on all levels of educational sys- tems. Actually, rather than helping weaken the strong ties between social inequalities and educational trajectories, current political dynamics have increasingly come under the suspicion of further stabilizing them (Reay, 2017; Thompson, 2019). Our understanding of how exactly social orders and political formations play together in structuring educational inequalities is, however, still rather limited. How are inequalities in education defined and framed as a political issue? What understandings of educational justice inform these problematizations? How 
do political discourses become effective in everyday pedagogical practices, e.g., by justifying social sorting and exclusion, and thus patterns of inequalities? How do educational organizations react to political expectations and regulations regarding equity and equality in education, and what are (unintended) consequences of these reactions? How do broader political transformations structure dynamics of social disadvantaging in education?

Hence the objective of this thematic issue of Social Inclusion: to inquire into the manifold and intricate entanglements of politics and inequalities in education. The collected articles cover a wide range of fields in which such interplays become manifest: from non-formal education to school and higher education, from everyday pedagogical interactions to changing forms of governing educational inequalities, from media discourses to the "political arithmetic" of measuring educational inequality. This thematic variety mirrors an overriding ambition: Our goal was to bring together scholarship from different research areas and with diverse analytical and methodological outlooks in order to explore perspectives for conceptual and methodological innovation.

\section{Facing the Entanglements of Politics and Research}

The critical investigation of the politics of educational inequalities faces a dilemma that is perhaps best captured by the role of the OECD PISA surveys. On the one hand, PISA offers an important resource for demonstrating the scale and durability of educational disadvantages across the globe. The impressive amount of regular, comparative data offered by PISA (and other similar international "large scale assessment studies" such as TIMSS, PIRLS, or ICILS) were probably hard to imagine just a few decades ago. These data have played a crucial role in moving the issue of persistent educational inequalities to the fore of public and political debates.

On the other hand, PISA is itself part and parcel of an ongoing reconfiguration of educational inequalities; its power to represent educational inequalities (i.e., to define the methods as well as the terminology to monitor them) is linked to its role in governing them (Cowen, 2014). To start with, PISA and other assessment surveys focus on one dimension of educational inequality alone: attainment scores on psychometric competence scales. This exclusive focus comes at the price of neglecting various other dimensions and aspects of education. The narrowing of educational inequalities to performance measures in a few subjects also mirrors a specific and contested understanding of justice (Derouet, 1992; Francis et al., 2017). Conceptions of social justice that, for example, take processes of recognition or aspects of distributive justice into account and thus go beyond purely economic understandings of "equity of opportunities" have become marginalized (Lingard et al., 2014). These developments affect professional self-understandings, pedagogical practices, and teaching content (Høvsgaard Maguire, 2019; Ratner et al.,
2019). Further, instruments of accountability are being redefined in these terms-not only students, but also schools and teachers are increasingly being assessed based on standardized achievement tests of students' performance (Auld et al., 2019; Niemann \& Martens, 2018; Seitzer et al., 2021).

In a nutshell, the core problem is that PISA and other parts of our daily "research infrastructure" do not merely provide a neutral representation of a reality external to them, they are themselves constitutive and expressive of educational orders that are deeply entangled with political and social relations. Critical researchers may be fully aware of these social entanglements-in many situations they nonetheless need to rely on these very infrastructures if they wish to analyze patterns of disadvantaging. Educational research itself has thus become fixed in a powerful epistemic and empirical configuration in which research on inequalities is narrowed to the measurement of educational outcomes, the effects of which are deeply intertwined with conceptions of "fair and good education," pedagogical practices, curricula design, professional self-understandings, evaluation and accountability mechanisms, and educational governance.

\section{From Achievements to Epistemic Orders and Educational Arrangements}

The demand to reconsider the interplay of politics and inequalities in education implies that we need to move beyond the standard model of problematizing and explaining educational inequalities. One foundational characteristic of this standard model is that inequalities are conceived of as purely external to educational systems, as always already there and then only reproduced in schools and universities. In this model, educational organizations are imagined as passive actors that struggle to respond to overburdening social dynamics and unequal living conditions.

The starting point of Marcus Emmerich's and Ulrike Hormel's article "Unequal Inclusion: The Production of Social Differences in Education Systems" is that we need to overcome this presupposition and rather focus our attention on how inequalities are construed and produced "on the inside" of education systems (Emmerich \& Hormel, 2021). Emmerich and Hormel draw on Charles Tilly's relational sociology of social inequalities and Niklas Luhmann's differentiation theory to decipher how particular "observation regimes" arise in educational systems. These observation regimes structure how educational organizations (such as schools) perceive and handle "external" social categories, mapping and matching them with processes and requirements that arise from the structures and logics of educational institutions themselves. Using various examples from their empirical research in schools in Germany and Switzerland, the authors demonstrate how such an analytical perspective helps understand current dynamics of differential inclusion and social closure in education. 
There is an important takeaway message in Emmerich and Hormel's argument that resonates with the other articles in this thematic issue. Irrespective of the underlying social theory and the methodological approach, there are two main strategic anchor points for advancing our understanding of the politics of educational inequalities: epistemic orders and organizational forms.

In this sense, in their article "Education and 'Categorical Inequalities': Manifestation of Segregation in Six Country Contexts in Europe," Başak Akkan and Ayşe Buğra put the emphasis on how access to school education is organized differently in different national contexts (Akkan \& Buğra, 2021). Their qualitative comparison of six European education systems addresses a true conundrum: why there is so much similarity across Europe in how vulnerable populations are systematically hindered in developing their full educational capabilities in spite of a wide variation in social structures and education systems. Building on the conceptual framework of "schools as sorting machines" (Domina et al., 2017), Akkan and Buğra speak of educational arrangements to grasp these dynamics - in particular different forms of segregation, privatization of public schooling and freedom of school choice that lead to diverse, yet durable "mechanisms of injustice." They argue that these arrangements also help understand why the very instruments designed to deal with social and cultural diversity can end up (re-)producing patterns of exclusion in education. They thus illustrate both the need and the productivity of moving from conceiving of inequalities solely in terms of achievements (as measured by standardized tests) to analysing concrete, complex, conditioned, and contextual arrangements that promote or hinder equal access to education.

Switching from achievements to arrangements opens a range of novel research perspectives because it directs our attention to issues that tend to be neglected in dominant debates on educational inequalities. For example, Lea Fobel and Nina Kolleck's article "Cultural Education: Panacea or Amplifier of Existing Inequalities in Political Engagement?" invites us to reconsider the potentially equitable role of cultural education. Their article makes a triple shift in comparison to dominant forms of thinking about educational inequalities: First, they do not focus on a high-stakes subject (such as mathematics); second, they investigate non-formal educational settings instead of formal educational institutions; and third, they do not restrict their analysis to achievements as dependent variable, but rather focus on the effects of cultural education on political engagement (Fobel \& Kolleck, 2021). Using empirical data from the German National Education Panel Study (NEPS), they show that cultural education indeed does affect levels of political engagement; however, access to and participation in non-formal cultural education is distributed unevenly across social groups. These patterns matter because they lead to fundamental questions regard- ing the role of education for social cohesion and political belonging. They also illustrate the equitable potential of providing a broad, general, and equal education that includes cultural education for all from an early age onwards.

Using epistemic orders and educational arrangements as entry points to unravel structures and processes of durable inequalities in education opens a wide spectrum of topics for empirical research. Among the crucial phenomena that deserve attention are changing conceptions of educational justice and forms of reasoning about "good and fair education," strategies and tactics of explaining and justifying educational disadvantages, the emergence and transformation of categories and classifications that are employed in political and pedagogical contexts, the rules and regulations that constrain and enable everyday pedagogical interactions, the fads and foibles of permanent educational reform, or the spatial and temporal organization of education. All these possible research topics define "interfaces" between politics and education: They are deeply marked by political orders and at the same time structure everyday pedagogical situations.

In his article "Mission Accomplished? Critique, Justification, and Efforts to Diversify Gifted Education," Arne Böker demonstrates the added value of focusing on such "interfaces." He discusses the case of the German Academic Scholarship Foundation-a foundation that supports "gifted students" in their university careers (Böker, 2021). On the basis of official documents that span almost a century, Böker investigates how this foundation has responded to criticisms of social selectivity, and how this response has evolved over timeillustrating how this specific educational organization makes strategic use of existing epistemic orders, statistical procedures, and emerging testing infrastructures for justifying its selection practices. This strategic agency ends up reproducing the very patterns of selectivity that it purportedly meant to overcome. One of the key insights of Böker's analysis concerns the role of plurality in understandings of what defines justice and merit in education: social actors seem keen and capable of making strategic use of this plurality.

Epistemic orders and organizational arrangements do not only delineate the strategies of educational actors, they also affect students' biographies and selfunderstandings. This is the key argument that Stephan Dahmen develops in his article "Constructing the 'Competent' Pupil: Optimizing Human Futures Through Testing?" Dahmen discusses the introduction of so called "analyses of potentials" as key element of the transition system between compulsory education and the labour market in Germany (Dahmen, 2021). He discusses the political and epistemic context of this development: the shift towards neoliberal political rationalities that leads to the construal of "competency" as foundation for forming and assessing students as self-reliant and responsible subjects. Structural barriers and power relations in 
getting an apprenticeship become hidden from sightnotwithstanding the essential role of this instrument for forming students' subjectivities by, for example, "cooling aspirations down" into "realistic expectations" regarding their future career.

Dahmen's analysis demonstrates the decisive role of testing for the regulation of educational inequalities: Tests function as devices that shall ensure both differentiation and fairness at the same time. Romuald Normand's contribution to this thematic issue points to a related technology of assessment: the indirect quantification of inequalities in education through measuring intellectual capacities. His article "The New European Political Arithmetic of Inequalities in Education: A History of the Present" reconstructs the historical emergence of testing industries in education, from early intelligence testing to recent psychometric instruments in large scale assessment studies (Normand, 2021). His focus is on the political embedding of these evolving epistemic technologies: He illustrates how their development has been intertwined with changing forms of educational governance and broad social transformations related to the modern welfare state. He argues that our current situation is characterized by political programs that focus on notions of competitiveness and human capital, amounting to a new political arithmetic of inequalities in education.

Educational arrangements always presuppose actors involved in sustaining and transforming them. Thinking in arrangements of educational inequalities therefore allows to reconsider professional responsibilities as well as structural conditions and constraints of equitable educational practices. The final three articles in this collection move in this direction by shifting our attention to the interplay of political logics, professional orientations, and pedagogical practices.

Laura Behrmann's article "'You Can Make a Difference': Teachers' Agency in Addressing Social Differences in the Student Body" asks whether and under what circumstances teachers in Germany consider social responsibility an essential element of their professional self-understanding. Based on her empirical research, Behrmann identifies four types of action orientation that prove highly productive for thinking about the interplay of organizational settings, teacher biographies, and professional self-understandings (Behrmann, 2021). Asserting a generally low inclination of seeing the counterbalancing of social disadvantages as key part of their job, she discusses conditions under which such a consciousness of social responsibility does become more likely. Among others, she underlines the relevance of teachers own biographical experiences as well as the importance of a school culture that is conducive to critical engagement with students' social backgrounds.

In her article "Study Preparation of Refugees in Germany: How Teachers' Evaluative Practices Shape Educational Trajectories," Stefanie Schröder focuses on the (often blocked) transition of refugee students into higher education. Her analysis is inspired by the soci- ology of valuation and evaluation-a perspective that leads her to focus on the processes of categorization and justification that inform and stabilize patterns of assessing the potentials and performances of refugee students (Schröder, 2021). Based on extensive qualitative interviews with involved teachers, Schröder provides important and timely insights on how teachers' experiences and perceptions as well as institutional norms and rules become effective in whole series of test situations that eventually structure the educational trajectories of a group of students who often are in a socially vulnerable and disadvantaged position.

Nadine Bernhard's article "Students' Differences, Societal Expectations and the Discursive Construction of (De)Legitimate Students in Germany" puts the analytical emphasis on public discourses that become effective in the pedagogical field in the form of expectations concerning the fairness and quality of education (Bernhard, 2021). More specifically, she asks how higher education institutions process social categories and how they get to know (or not to know) about their students in terms of these categories. Based on a content analysis of media outlets and professional journals and building on neoinstitutional organizational sociology, she diagnoses a crucial difference between social categorization in higher education in comparison to school education: students' social backgrounds are still effectively de-thematized in higher education, with categorization being organized around notions of competencies and performances.

\section{Acknowledgments}

We would like to thank all our authors for their dedication and constructive collaboration throughout the review and publication process. The quality of the final articles is, however, also due to the tremendous effort of our reviewers. Their insightful, detailed, and constructive remarks, suggestions, and assessments deserve all the more acknowledgement considering that Social Inclusion does take the aim of ensuring not only a rigid, but also a speedy review process seriously. Our special thanks, finally, goes to Mariana Pires and the editorial team for their highly reliable and professional support from the first steps to the final publication of this issue of Social Inclusion.

\section{Conflict of Interests}

The authors declare no conflict of interests.

\section{References}

Akkan, B., \& Buğra, A. (2021). Education and "categorical inequalities": Manifestation of segregation in six country contexts in Europe. Social Inclusion, 9(3), 313-323.

Auld, E., Rappleye, J., \& Morris, P. (2019). PISA for development: How the OECD and World Bank shaped edu- 
cation governance post-2015. Comparative Education, 55(2), 197-219.

Behrmann, L. (2021). "You can make a difference": Teachers' agency in addressing social differences in the student body. Social Inclusion, 9(3), 372-382.

Bernhard, N. (2021). Students' differences, societal expectations and the discursive construction of (de)legitimate students in Germany. Social Inclusion, 9(3), 394-403.

Böker, A. (2021). Mission accomplished? Critique, justification, and efforts to diversify gifted education. Social Inclusion, 9(3), 337-346.

Cowen, R. (2014). Ways of knowing, outcomes and "comparative education": Be careful what you pray for. Comparative Education, 50(3), 282-301.

Dahmen, S. (2021). Constructing the "competent" pupil: Optimizing human futures through testing? Social Inclusion, 9(3), 347-360.

Derouet, J.-L. (1992). Ecole et justice: De l'égalité des chances aux compromis locaux? [School and justice: From equal opportunities to local compromises?]. Editions Métailié.

Domina, T., Penner, A., \& Penner, E. (2017). Categorical inequality: Schools as sorting machines. Annual Review of Sociology, 43(1), 311-330.

Emmerich, M., \& Hormel, U. (2021). Unequal inclusion: The production of social differences in education systems. Social Inclusion, 9(3), 301-312.

Fobel, L., \& Kolleck, N. (2021). Cultural education: Panacea or amplifier of existing inequalities in political engagement? Social Inclusion, 9(3), 324-336.

Francis, B., Mills, M., \& Lupton, R. (2017). Towards social justice in education: Contradictions and dilemmas. Journal of Education Policy, 32(4), 414-431.

Høvsgaard Maguire, L. (2019). Adapting to the test: Performing algorithmic adaptivity in Danish schools. Discourse: Studies in the Cultural Politics of Education, 40(1), 78-92.

Lingard, B., Sellar, S., \& Savage, G. C. (2014). Rearticulating social justice as equity in schooling policy: The effects of testing and data infrastructures. British Journal of Sociology of Education, 35(5), 710-730.

Niemann, D., \& Martens, K. (2018). Soft governance by hard fact? The OECD as a knowledge broker in education policy. Global Social Policy, 18(3), 267-283.

Normand, R. (2021). The new European political arithmetic of inequalities in education: A history of the present. Social Inclusion, 9(3), 361-371.

Ratner, H., Andersen, B. L., \& Madsen, S. R. (2019). Configuring the teacher as data user: Public-private sector mediations of national test data. Learning, Media and Technology, 44(1), 22-35.

Reay, D. (2017). Miseducation: Inequality, education and the working classes. Policy Press.

Schröder, S. (2021). Study preparation of refugees in Germany: How teachers' evaluative practices shape educational trajectories. Social Inclusion, 9(3), 383-393.

Seitzer, H., Niemann, D., \& Martens, K. (2021). Placing PISA in perspective: The OECD's multi-centric view on education. Globalisation, Societies and Education, 19(2), 198-212.

Thompson, R. (2019). Education, inequality and social class: Expansion and stratification in educational opportunity. Routledge.

\section{About the Authors}

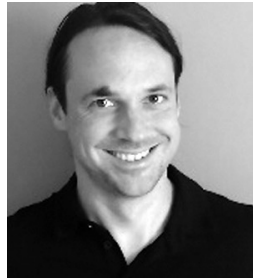

Kenneth Horvath is a postdoc researcher at the University of Lucerne, Switzerland. His current research focuses on current trends and dynamics in educational inequalities, paying specific attention (1) to educational disadvantaging in contexts of migration and racism and (2) to the social implications of digitization and datafication of education. His second key interest is on the methods and methodologies of social research.

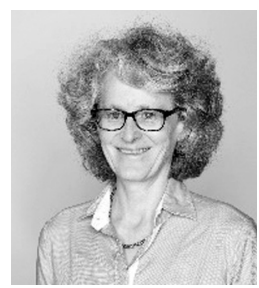

Regula Julia Leemann is a professor of sociology of education at the University of Teacher Education FHNW and adjunct professor at the Institute for educational sciences, University of Basel. Her main research areas are educational governance, transformation of educational institutions, educational and academic trajectories, educational inequalities, vocational education and training (VET), and educational organisations. 